\title{
Embodied Demonstratives: A Reply to Wu
}

\author{
Christopher Mole \\ University of British Columbia \\ cmole@mail.ubc.ca \\ PENULTIMATE DRAFT - FINAL VERSION FORTHCOMING IN MIND
}

\begin{abstract}
Although Wayne Wu correctly identifies a flaw in the way in which my 2009 article frames the debate about 'zombie action', he fails in his attempts to strengthen the case for thinking that our actions are under less conscious control than we usually imagine. His argument, like the arguments that my earlier paper addressed, can be blocked by allowing that an embodied demonstrative concept can contribute contents to a visual experience.
\end{abstract}

In 'Illusions, Demonstratives, and the Zombie Action Hypothesis', I followed David Milner and Melvyn Goodale by stating the philosophically challenging part of their two visual system hypothesis as being the claim that 'the visual system that gives us our visual experience of the world is not the same system that guides our movements in the world' (Goodale and Milner 2004, p. 3, cited in Mole 2009a, p. 995).

Wayne $\mathrm{Wu}$ complains that this way of putting things obscures the point that is really at issue. The philosophical debates that Milner and Goodale have prompted are not 
primarily concerned with the sameness or distinctness of systems. Those debates should instead be understood as being concerned with the consciousness or unconsciousness of the representations that 'directly control and guide mundane bodily actions'. Once this clarification is in place, Wu thinks, the arguments that I deploy against Milner and Goodale's position can be resisted.

About the first of these points Wu is certainly correct: The sameness and distinctness of systems is something of a red herring in the present context. About the other points, he is mistaken. The mistake is largely the result of a failure on my part: My earlier discussion was far too perfunctory in giving its account of what it is for an embodied demonstrative to contribute content to a visual experience. Since the notion of embodied demonstration was crucial to my reasons for resisting the zombie action story, I give a somewhat fuller account of that notion in section two, below.

\section{The point at issue}

Before turning to the account of embodied demonstratives, let us first address the point that $\mathrm{Wu}$ is certainly right about. My discussion focused on the claim that 'the visual system that gives us our visual experience of the world is not the same system that guides

our movements in the world'. But to deny that claim is not yet to have said anything at all — still less to have said anything that is philosophically contentious - until that denial has been supplemented with some criterion by which systems are to be individuated. I have given no such criterion, and do not know how to give one, other than as a merely verbal stipulation. $\mathrm{Wu}$ is therefore right to say that the sameness of systems cannot be the 
point that is really at issue in the debates about 'zombie action'. If that were the issue, the debates would turn on a merely verbal point.

Wu's own account of the issue that should be in dispute is rather less convincing. He suggests that the issue can be made precise by considering a pair of theses, one of which he calls the 'Minimal Thesis', and one of which he calls the 'Strong Thesis'. His 'Minimal Thesis' states that 'some visual representations that directly control and guide mundane bodily movements are unconscious'. His 'Strong Thesis' states that most of them are.

In order to see that neither of these theses successfully captures the point that is really in contention, it is helpful to be more careful than we usually are when talking about the consciousness of representations. Several philosophers of mind have made the point that when we call a representation conscious, we transfer an epithet to it that more properly belongs to the subject in whom that representation is employed (see, for example, Bennett and Hacker 2003). A representation of $x$ is a conscious representation just if there is a subject who is conscious of $x$ on account of $x$ being the content of that representation. (The 'on account of' here should be understood to mean 'immediately on account of'; that is, the representation's having the content $x$ must make it the case that the subject is conscious of $x$ without needing to cause any mediating representation to have that content along the way.)

With this in mind, consider the sorts of action that Milner and Goodale are concerned with. Their studies concern simple, visually guided acts, such as the act of picking up a disk that is clearly in view on the table in front of one. $\mathrm{Wu}$ and others think that these acts 
have been shown to be under the control of the 'zombie within'. The commonsense description of such actions - the non-zombie description that Wu takes Milner and Goodale's work to refute - is as actions in which the agent is conscious of the disk on which she acts, and in which her conscious awareness of the disk explains her acting as she does. Having reminded ourselves that a conscious representation of $x$ is just a state in virtue of which the subject is conscious of $x$, it should be clear that this commonsense description requires the agent to have a conscious representation of the disk that she picks up, and requires that this representation makes some explanatory contribution (there is room for dispute about how much of one) to the agent's movement. The commonsense view also requires that the subject's conscious representation encodes quite a lot of information, about the disk's, size, shape, and location. But it does not require the subject to have more than one such representation. Nor does it say anything about whether, in the course of doing its action-producing work, the subject's representation might generate other representations, perhaps lots of them, that do not contribute to consciousness at all. The commonsense picture is therefore quite compatible with Wu's 'Minimal Thesis', and with his 'Strong Thesis'. Even if both of these theses were established, that would not establish anything that is revisionary of commonsense, or anything that is deserving of the name of 'zombie action'. Wu is therefore mistaken in thinking that these theses identify the philosophical point that Milner and Goodale's work brings into contention.

We can find a more satisfactory account of the point that should be in contention if we turn to the work of Milner and Goodale themselves. Their work is philosophically provocative because it suggests a mild version of epiphenomenalism: It suggests that the causal chains leading to our experiences occur on branch lines from the causal chains that 
bring about our actions on the things that are experienced. In their epilogue to the 2006 edition of The Visual Brain in Action, Milner and Goodale put the point like this:

[W] hen carrying out a visuomotor act a person is typically visually aware of the stimulus to which their action is directed, and of the limb that is making that action. It is our claim ... that all of this visual awareness will be mediated by processing in the ventral stream and that this processing will typically unfold independently of, and in parallel with, the visual control of action itself. (Milner and Goodale 2006, p. 222)

Philosophers have been particularly impressed by two of the lines of evidence that Milner and Goodale offer in support of this claim: They have been impressed by the evidence from visual form agnosia, and they have been impressed by the evidence from the Ebbinghaus reaching effect. My 2009 article was intended to show that Milner and Goodale's claim is not supported by either of these lines of evidence. Neither of them gives us a reason to think that all visual awareness is mediated independently of the visual control of action. Even when both lines of evidence are accounted for, it remains likely that some visual awareness (specifically, our visual awareness of the particular ways in which items in our environment afford accusative actions) may result from the processing by which our actions are visually controlled. Nothing in Wu's response requires this position to be revised.

\section{Embodied demonstratives}

The idea that is crucial in blocking the case for zombie agency is the idea that an embodied demonstrative can contribute contents to a visual experience. When properly 
understood, this idea blocks Wu's version of the argument from Ebbinghaus reaching, just as it blocks the arguments that I considered previously, but it is an idea that can best be seen (reversing the order of my earlier exposition) by first considering the way in which it applies to the case of DF, the visual form agnosic.

All parties in the current debate agree that, when presented with a letterbox-like slot in a context where there is no action to be performed on that slot, DF experiences the slot, but does so in a way that provides her with no information about the slot's orientation. It is also agreed that, when DF is presented with the slot as a target for action, information about its orientation contributes to the way in which her actions are performed. In order to account for this, Milner and Goodale propose that DF's actions are guided by representations of the slot's orientation that make no contribution to her consciousness. I do not think that this hypothesis provides the best explanation of the data. My suggestion is that DF's capacity to act on the slot, and on other things around her, and, more specifically, her capacity to act on these things spontaneously and naturally, is better explained by saying that DF's actions are guided by representations of the slot's orientation that $d o$ make a contribution to consciousness, but that these representations have a format that is immediately useful only for informing DF of how the slot should be acted upon. For any purposes other than reaching, they do little to enhance DF's epistemic position with regard to the slot's orientation. It may also be that, since they are of little use in other contexts, these representations are formed only when the slot is presented as a target for action.

The idea here is that the way in which orientation is experienced by DF is as the referent of a demonstrative concept that latches onto its content by means of an embodied gesture. 
Visual experience does not present her with the slot as vertical, or as being at ninety degrees, or as being oriented similarly to, or differently from, any other template line. Instead it presents her with the slot as being oriented so as to be acted on thus (where a bodily gesture is needed to specify the character by which this demonstrative thus picks out the orientation that is its referent).

An analogy may be helpful here. Suppose there is a slot before me, and suppose that you need to be informed of its orientation. I could communicate the orientation to you by drawing you a picture, or by telling you that it is horizontal, or that it is parallel to the floor, or at ninety degrees to the line that runs from your feet to your head. Any of these can communicate the orientation to you, although, given certain background beliefs, they might have different effects on your overall epistemic position with regard to that orientation. I might also make a posting gesture (of a sort that you can mirror) and tell you that the slot is oriented so as to be acted upon thus. My claim is that the way in which the slot is given to DF in visual experience is analogous to the last of these. When looking at the slot, as a target for action, she sees it as being such as to be acted upon thus, where this thus gets its character from a bodily gesture. It is on the basis of this conscious experience that she is able to act upon the slot, with just such a gesture. Her action is not a zombie action. It is under the control of a conscious experience that has this embodied demonstrative character.

One could put this point by saying that, according to my interpretation of her condition, DF visually experiences an affordance. That would not be inaccurate, but nor would it be the whole story. 'Affordance' is J. J. Gibson's word. As Gibson understands it, one’s environment can be perceived to afford various activities, but these need not be activities 
that are specified by the bodily actions in which they are realized. A surface can be perceived as affording support, for example, and a substance can be perceived as affording drinking (Gibson 1977, p. 68). My claim is not that DF perceives the slot as affording posting, but that she experiences it as affording one particular embodiment of posting: an embodiment through which the slot's orientation is identified.

The idea of an embodied demonstrative should not be mistaken for anything exotic or $a d$ hoc. Demonstratives of this sort are familiar from other contexts where practical modes of presentation need to be referred to. It is not unprecedented to think that they can contribute contents to perceptual experiences. We can see embodied demonstratives at work in experience when the pianist who is playing by ear hears a chord as being such as to be playable thus (where the thus here is given by a configuration of fingers on the keys). The pianist does not need to work out which configuration of his fingers is the right one for producing the chord that he hears. The chord is immediately given to him in perception (if he is appropriately situated with respect to a piano) as being thus-playable. If he has the job of transcribing the music that he is hearing, it may be that his best approach is to listen to a chord or two, to play along to them, and to make his transcription by reading off the notes from his subsequent observations of what his fingers are doing. Similarly, and somewhat more contentiously (see Fowler and Rosenblum 1991; Mole 2009b), a listener who is hearing a piece of speech that contains phonemes in her native language can hear a sound as being such as to be utterable thus (where the thus in this case is given by a gesture of the vocal apparatus). This bodily gesture gives the character of the demonstrative concept under which the sound is experienced. The gesture by which the sound can be produced is not inferred from a prior 
representation of the sound's acoustic profile. Instead, it is as producible by such a gesture that the sound is perceived.

In each of these examples it is clear that, in order for a gesture to contribute to the character of an experience, it is not necessary for the perceiver to already be performing that gesture. The pianist can hear that the chord is such as to be playable thus without yet having played it. The hearer of speech can hear a phoneme as being such as to be utterable thus, without needing to utter anything herself. This point is crucial if embodied demonstratives are to do the explanatory work that I have assigned to them. My earlier discussion of Schenk and Milner's experiments (Schenk and Milner 2006, cited in Mole 2009a, p. 1008) depended on the idea that DF is already employing an embodied demonstrative in experiencing the shape of the objects that she reaches for (that is, that she experiences the objects as being shaped so as to be reachable thus), before she initiates the action of reaching for them. This must be so since, in some of these experiments, the lights go out as soon as her hand leaves its starting place, giving her no visual experience of the target of her action once her reach is initiated. Similarly, as $\mathrm{Wu}$ notes, the Ebbinghaus reaching effect can occur in 'open-loop' conditions, where the lights go out as soon as a response is initiated. This requires embodied demonstratives to contribute to the content of an experience before any action is made on the basis of that experience. $\mathrm{Wu}$ thinks that this is impossible, and so that the embodied demonstratives can play no role in the open-loop condition. This is based on the mistaken idea that embodied demonstratives are available only after the gestures that give their character have been performed. 
There is very much more that might be said about embodied demonstratives, and about the way in which they can contribute to the content of experience. Much of it would surely be contentious, but I hope that I have already said enough to make it clear that Wu's reductio version of the Ebbinghaus reaching argument does nothing to establish that normal reaching behavior is zombie action. The first seven steps of Wu's attempted reductio are perfectly correct. Milner and Goodale are rightly taken to have established that, in order for conscious representations to be understood to play a role in the production of action, the disk on which the subject acts must be consciously represented as having two different sizes at once. But the supposition that is needed to turn this into an absurdity — the supposition that the disk on which the agent acts does not look to have two different sizes - is introduced by Wu purely as an assumption. There is no reason at all to think the disk is not seen as being two different sizes. It can be seen to be about so big (where the content of 'so big' is given as the distance from thumb to forefinger in a size-displaying gesture). At the same time it may be seen as being sized so as to be reachable thus (where the content of the 'thus' is given via an embodied demonstrative). Since the two different sizes are represented under two different modes of presentation, it may not be manifest to the subject that these sizes are different. There is therefore no reason to believe the premise that occurs as line eight of Wu's reductio. That argument therefore fails to get us from the Ebbinghaus reaching effect to the conclusion that normal reaching actions are in any way zombie-like.

In the final sections of his response $\mathrm{Wu}$ suggests that there is an additional onus faced by anyone who wants to resist the case for zombie action. He suggests that it is not enough to have shown that DF may be consciously experiencing the orientations of the slots 
through which she posts, or to have shown that a normal subject in that Ebbinghaus reaching experiment may be consciously experiencing the size of the disks he reaches for, in a way that could be controlling the grip-size with which he reaches for them. In addition to this, $\mathrm{Wu}$ suggests that I also need to show that these conscious, action-guiding experiences are visual experiences.

This suggestion certainly identifies a point where objections might be raised to some of the things that I have said. One might allow that embodied demonstratives can contribute contents to experience while refusing to allow that any experience to which they contribute can properly be described as visual. But to insist on this as a part of the case for zombie action would be to return us to a point where the whole debate will turn out to depend on an arbitrary verbal stipulation. If experiences with embodied demonstrative contents do not count as visual (despite the fact that they are mediated by light that is received by the eyes, and despite the fact that they do not involve smelling, hearing, touching, or tasting the things that are experienced) then nothing that I have said provides any challenge to the claim that I earlier identified as being our best account of the point that is in contention. Milner and Goodale's claim was that 'all ... visual awareness [of the items on which we act] will be mediated by processing in the ventral stream and that this processing will typically unfold independently of, and in parallel with, the visual control of action itself'. That claim could be saved by denying that embodied demonstratives can contribute to the contents of visual experiences, but, having been saved in that way, the claim can no longer be interpreted as a formulation of the claim that the zombie action theorist wanted to make. If the actions in the Ebbinghaus reaching paradigm, or the actions of the visual form agnostic, are to serve as the foundations of 
'the case for zombie agency', as Wu says that they do, then it must be established, not only that these actions can be controlled without visual awareness, but that they are controlled without any conscious awareness at all. I have shown this not to have been established.

University of British Columbia

Department of Philosophy

1866 Main Mall E370

Vancouver, BC,

V6T 1 Z1

Canada

cmole@mail.ubc.ca

CHRISTOPHER MOLE

\section{References}

Bennett, Max R. and Peter M. S. Hacker 2003: Philosophical Foundations of Neuroscience. Oxford: Blackwell.

Fowler, Carol A. and Lawrence D. Rosenblum 1991: 'The Perception of Phonetic Gestures’. In Mattingly, and Studdert-Kennedy 1991, pp. 33-68.

Gibson, James J. 1977: 'The Theory of Affordances'. In Perceiving, Acting, and Knowing: Toward an Ecological Psychology. Shaw, R. and Bransford, J. (eds) Hillsdale, NJ: Lawrence Erlbaum pp. 67-82. 
Goodale, Melvyn A. and A. David Milner, 2004: Sight Unseen. Oxford: Oxford University Press.

Mattingly, Ignatius G., and Michael Studdert-Kennedy (eds) 1991: Modularity and the Motor Theory of Speech Perception: Proceedings of a Conference to Honor Alvin M. Liberman. London: Routledge.

Milner, A. David, and Melvyn A Goodale 2006: The Visual Brain in Action. Oxford: Oxford University Press.

Mole, Christopher 2009a: 'Illusions, Demonstratives and the Zombie Action Hypothesis'. Mind, 118, pp. 995-1011.

_ 2009b: 'The Motor Theory of Speech Perception'. In O’Callaghan and Nudds 2009, pp. 211-33.

O’Callaghan, Casey and Matthew Nudds (eds) 2009: Sounds and Perception: New Philosophical Essays. Oxford: Oxford University Press.

Schenk, Thomas and David A. Milner 2006: 'Concurrent visuomotor behavior improves form discrimination in a patient with visual form agnosia'. European Journal of Neuroscience, 24 (5), pp. 1495-503. 